\title{
Reconstruction of the Media Law of the Era of Industry Revolution 4.0 Elections
}

\author{
Eddhie Praptono*, Erwin Aditya Pratama \\ Faculty of Law \\ University of Pancasakti Tegal \\ Tegal, Indonesia \\ *praptonolaw@gmail.com
}

\begin{abstract}
Indonesia election in 2019 attracted great attention, began a large humanity event where 554 general election officers who passed away to spend a large budget to hold the elections Simultaneously of $\mathbf{2 . 4}$ trillion. Elections in Indonesia are organized using conventional methods, namely by striking or contrard of voice mail that complicate voters and electoral officers in counting voice mail. As a comparison of developed countries such as the United States have leverages the electronic collaboration voting and the Internet as a medium for the public to vote and the media counting the voice mail for electoral officers so that the elections there Practically only takes time, energy, and budget ideally. The presence of the Internet as a trigger part of the Industrial Revolution 4.0 need to be addressed by the Government as a medium for the retrieval and counting of voice mail and voice counting so that the human tragedy and waste of state budget can be minimized in Electoral organization. Through the ruling Constitutional Court Verdict No. 147/PUUVII/2009 is the best juridical road to the general elections utilizing the 4.0 Industrial Revolution. Hopefully, this research can open the way of mind for the implementation of the elections in Indonesia.
\end{abstract}

Keywords: general elections, electronic voting, industrial revolution 4.0

\section{INTRODUCTION}

The simultaneous elections in Indonesia were held in 2019 to attract great attention, starting a major humanity event where 554 general election officers passed away to spend a large budget to hold elections Simultaneously of 2.4 trillion. Elections in Indonesia are organized using conventional methods, namely by Striking or contrard of voice mail that complicate voters and electoral officers in counting voice mail. General elections in Indonesia siphon large energy, especially the cost and energy to distribute the voice mail throughout the vast archipelago area [1].

Elections (election) is an integral part of Indonesia as a democracy, because it is the process of voicing people's sovereignty and limiting power. The Constitutional Court ruling. 147/PUU-VII/2009 gives a new hope that the elections can be held using the electronic voting as a media of the implementation of democracy in Indonesia with the requirements to be fulfilled. Voting Media is an important part of the electoral process, this is because this activity will result in the implementation of the elections in accordance with the principle of election enforcement.

The problems mentioned in the first paragraph indicate the weakness of the elections in Indonesia using manual and based on the sound paper, responding to the thought of carrying out the General use electronic voting system in Indonesia as already used by the big state such as in the continental Americas and Europe. E-voting itself comes from the word electronic voting that refers to the use of information technology on the conduct of voting, on electronic voting using hardware technologies such as computer screens, computer processors, and software IE software or computer programs itself, nowadays electronic voting can also be utilized using internet technology sourced from the website [2].

The rapid development of electronic technology and Internet-based communication today, brought a thought to contribute in resolving problem in the general elections that occurred in Indonesia. This is considered to be effective considering the function of the Internet that has been widely used in areas such as economy, government, education and health, as well as various benefits in get from the internet such as ease of access communication Effective, fast and efficient in providing information. Based on this, it is evident that an electoral system uses an electronic voting system to facilitate the general election activities in Indonesia and minimize the barriers that exist in the current elections [3].

As a comparison of developed countries such as the United States have leverages the electronic collaboration voting and the Internet as a medium for the public to vote and the media counting the voice mail for electoral officers so that the elections there Practically only takes time, energy, and budget ideally. The presence of the Internet as a trigger part of the Industrial Revolution 4.0 need to be addressed by the Government as a medium for the retrieval and counting of voice mail and voice counting so that the human tragedy and waste of state budget can be minimized in Electoral organization. Through the ruling Constitutional Court Verdict No. 147/PUU-VII/2009 is the best juridical road to the general elections utilizing the 4.0 Industrial Revolution. The purpose of this research is to find out how effective electronic media voting is used for general elections in Indonesia and the readiness of Indonesian Society welcomes the general elections using electronic media [4]. 


\section{FORMULA PROBLEMS}

- How to study the law of elections using Electronic voting in Indonesia?

- How is the development of the appropriate electoral media in accordance with the Times and principles of openness?

\section{ReSEARCH Methods}

This research is a Socio Legal approach. The legal socio approach is used to analyse the various laws and regulations related to elections by using e-voting. Meanwhile, the socio legal Research approach is a study that refers to the norms and legal principles contained in the legislation and court decisions/facts in the field. Ronald Dworkin called the research method as well as doctrinal research (doctrinal research), a study that analysed both laws as law as it written in the book, as well as law as it is decided by the judge through The judicial process [5].

Three reasons for using empirical legal research are qualitative. Firstly, qualitative analysis is based on the paradigm of dynamic relationships between theories, concepts and data which is a constant feedback or modification of the theories and concepts based on those gathered. Secondly, the data to be analysed is diverse, having different basic properties among one another, and not easy to be quantised. Third, the basic nature of data to be analysed in the research is comprehensive and is an integral entity, where it demonstrates the diversity of data and requires in-depth information (indepth information) [6].

All three of these qualitative research criteria are found in this thesis study, so it is very reasoned to use qualitative methods in data analysis. This research is thorough because it seeks to deepen overall. The research also seeks to seek harmonious relationships from concepts found in primary and secondary legal materials using theory or legal doctrines [7].

\section{DISCUSSION}

\section{A. Study on the Electoral Law to Utilize Electronic Voting in Indonesia}

In a previous study conducted by Erwin Aditya Pratama in his journal Effectiveness of village head selection using electronic voting in Indonesia, his research explained that the elections to use electronic media voting in Indonesia has a very large benefit one of them is the efficiency of cost time and energy but need to be prepared human resource ability to conform with the development of technology.

Electronic information in question is any type of data that is electronic that has been processed, understandable. and has a form and meaning. The meaning of this sense has its meaning. Electronic information stored in the storage media is hidden. Electronic information can be identified and substantiated from the existence and meaning of electronic information [8].

Further to secure electronic information in the general elections in order not to be worn by the uninterested it is necessary a mechanism that is electronic signature. Pursuant to article 1 item 12 of the ITE Law, an electronic signature is a signature consisting of electronic information attached, associated or linked with other electronic information used as a verification device and Authentication. Like a regular signature, an electronic signature can be created or obtained from a wide variety of methods and technologies throughout the function as a verification and authentication tool. The meaning of electronic hands may be used to identify the signatory associated with the information and/or electronic documents, and to indicate the signatory approval of the electronic information. For example, many Internet users who perform a transaction on the site do not understand that by clicking on the "Yes" or "I agree" or "Accept" icon, then he/she is deemed to have agreed to the terms and conditions set out in the electronic contract, as the Customer's signature. By clicking on the icon, the consumer becomes legally bound to the transaction it does. Based on understanding and function, electronic signatures can be the action of pressing the icon "Yes " or "I accept ", Wet signature scanned (scan), use of Personal Identification Number (PIN), signatures using the technique kritography; Signatures using biometric techniques (biometric signatures are electronic signatures that use a person's unique characteristics in conducting verification and authentication) [9].

Along with the development of technology, signatures are also evolved from making up to their use. If you have noticed some users who use signatures at the end of his writing. Of course it's not the actual signature engraved with the pen Typically, these technologies are called digital signatures (digital Signature). A digital signature is a replacement for the electronic signature that is electronically and has the same function as a manual signature. Digital signatures are also series of bits created by conducting electronic communications [10].

An electronic signature has its correlate with a digital signature. A digital signature is an electronic signature that uses cryptographic techniques. In other words, a digital signature is part of an electronic signature. A digital signature is created and verified using this technique, the message is transformed into an unreadable shape and can be restored to its original form if the message is opened with the correct key. This is a digital signature used to guarantee that the received message comes from the right sender. A Digital signature allows someone to make a signature to all parties who know the public key. Some examples of signatures are only computesafe for the signing party, as they can be forged by those with large compute capabilities. If a signature can be forged, it will be difficult for the sender to convince the recipient of the signed document or the third party that he or she does not create the signature. When two people will exchange data securely, for example e-commerce. They send each other a key, which is the public key while the private key is a pair of the public key. So when sending data on an e-commerce network, the document can only be encrypted and defiled by using its partner key so that the data is transmitted securely on the public network. With digital signatures in the e-commerce network, users know the electronic data of an e-commerce service originated. The integrity of the message occurs because of the Digital Certificate. 
B. General Elections in Accordance with the Development of the Times and Principles of Openness

The application of e-voting is expected to address issues arising from conventionally convened elections. Riera and Brown as well as de Vuyst and Fairchild offer the benefits to be gained in the application of e-voting as follows [11]:

- Accelerate the counting of votes;

- The results of the vote counting are more accurate;

- Save the mold material to the sound paper;

- Save the cost of shipping the sound paper;

- Provide better access to people with disabilities (disability);

Electronic election system cannot be separated from the importance of confidentiality and security means, if confidentiality and security are fulfilled, then the e-voting is very appropriate to use. The e-voting method is not the only secure system, although this is the best for now. The main issue of E-voting is the risk aspect, including its relevance with confidentiality as well as security because technology applications that utilize the Internet are very vulnerable to hackers. From the fact of the disclosure cases of ATM Bank's breach some time ago that can be done very easily through the skimmer then the e-voting is also very range in the Bobol. This understanding is therefore very reasonable because of the importance of building a system for a safer electoral process without exclusion of transparency and accountability.

For Indonesia in general the time span of Democratic Party implementation from legislative elections to the presidential election then the elections should provide excitement for the people, but the Democratic Party can also trigger anxiety sociopolitical if The implementation is not as expected. Therefore, the party of democracy must be implemented transparently. The problem that occurred about the list of permanent voters or DPT that occurred in the elections yesterday should be a valuable lesson for the future implementation of the Democracy party so that the Democratic Party itself can run smoothly from the beginning until The end without any dispute covering it. Indonesia's vast geographical condition becomes a problem in itself related to the distribution of voice mail and all related to the implementation of democratic parties. There are even areas that have not yet done the process of the This condition certainly should be quick to think about how Democratic Party implementation can be implemented in real time online and there are no more reasons for space and time constraints. In addition, another consideration that advances in technology as well as Internet availability can be the main reason to no longer suspend the implementation of online democracy parties. Basically, e-voting is very possible to implement. The selection of using sound paper requires a lot of resources, energy, and time especially in the process of voice calculation. By using digital selection or e-voting can save time and effort used especially in the process of voice calculation [12].

The COURT ruling does not grant the applicant to execute the e-voting, but article 88 which explicitly mentions "Striking" is not revoked. The MK states that the article remains constitutionally as long as the e-voting method does not violate the Luber principle and the Jurdil, and the area that implements the E-voting method is readily available in terms of technology, financing, human resources, and software, readiness Areas in particular, as well as other necessary requirements. The MK gave a wider interpretation of article 88 , in line with the CONSTITUTION of 1945. Based on this, the MK, in its verdict, actually mentions the legal basis of the evoting implicitly. It is hoped that ways outside of Pencoblosan or Penticangan are accommodated by the legislator [10].

In line with this Purwanto added that to implement e-voting implementation in Indonesia, it takes a lot of improvement in the field of life. The improvement should begin by improving the education system, so that the level of public knowledge about information technology is better. Another serious problem should be done on the technology infrastructure currently owned, so that the implementation of the E-voting is not wasted. Other improvements should also be made to the voting support system; such as repairs to the population registration system. This will make it easier for the collection of citizens who have the right to vote. This improvement should be done as soon as possible, considering the magnitude of the role of information technology in our lives. If you experience a lag in information technology, Indonesia will face difficulties in competition with other countries. The Constitutional Court's decision to allow the use of e-voting could lead to the advancement of information technology in the homeland and to bring great savings in election financing. However, before applying, the use of electronic sound machines that need to be defined procedures and legal bases [13].

Purwanto further confirms that based on the results of the 2013 simulation experience for the implementation of the elections, security technology is very necessary to be added. Before use, the software that is in the machine it needs to be inspected by an independent agency, that there is no cheating in it and the software is locked by an independent institution. After the selection, the software must be checked again. If a software key change occurs, the system inside the machine is changed. This condition is an indication of the data manipulation that has been stored in the machine. The organization of the election machine also must be ensured. If the machine does not work suddenly or there is damage, such as the result of the power outage, the person who has the right to fix should be determined clearly. It is not permissible for any person to do so because it concerns the confidentiality of data therein [14].

The use of electronic selection machines can indeed encourage the implementation of an election that is cheap, effective, and simple. However, before the machine is used instead of striking, it is necessary to redefine the rules first. The Elections Commission needs to immediately publish rules governing the use of the new system and determine the ordinances and the validity of the vote through electronic selection machines. Without a clear legal basis, the validity of the use of electronic sound machines could cause chaos [12]. 
E-Voting is required for the preparation of the human resources, management data, procedures and the e-voting device itself, requiring the configuration of the list of voters and candidates before voting, Implementation of voting and voting in the TPS, and the delivery and recapitulation of the overall vote. Further, it is necessary to socialize with voters and candidates, the provision of e-voting devices, electronic voting simulations and sound calculations, and device certifications to ensure a direct, public, free and confidential and honest election principle and Fair can be fulfilled. The socialization of the use of new ways in elections also needs to be eliminated [10].

Basically the effectiveness of the general elections by using electronic Voting is a level of success in achieving objectives in selecting a fair, clean and transparent leader so that the results are accepted by all stakeholders [15]. When the person who wants to know the extent of the success of the general election by using electronic Voting, it must first be able to measure the extent to which the law is adhered to or not obeyed. But it is not yet a valid foundation of the effectiveness of the law, because to obey the rule of law, depending on its importance. In this interest has a variety of properties, namely [16]:

- Compliance: Obedience that is only afraid of sanctions, so that in this case the obedience to the law is very low because it requires continual supervision;

- Identification: Legal observance to maintain good relations with officers;

- Internalization: The adherence that really fits perfectly with the Intrinsic value he has, the degree of obedience is very high.

In the definition of legal effectiveness is not regulated in the legislation, but there is a legal expert opinion that describes the definition of this effectiveness, as Soerjono Soekanto suggests that effectiveness comes from the word effectives that means the extent to which a group reaches the goal.

Objectively, we can only assert that the deeds of the people are appropriate or not in accordance with the legal norms. Thus, the only connotations that are attached to the "effectiveness" of the law is that the real deeds of the people according to the legal norms. Based on the effectiveness of the above, then in this research can be concluded that the effectiveness of the meaning of achieving the objectives, goals or results of pre-defined activities. In other words, effectiveness is a comparison of results with what has been predetermined. Effectiveness is related to the achievement or outcome of the construction of street vendors [17].

In line with the explanation above, according to Soerjono Soekanto, the theory of legal effectiveness is that the effective or absence of a law is determined by 5 (five) factors, namely [17]:

- Its own legal factor (law);

- The factors of law enforcement, the parties who form or apply the law;

- Factors that support law enforcement;
- Community factors, namely the environment in which the law applies or applied;

- Cultural factors, namely as a masterpiece, copyright and flavour based on the human Carsa in the Association of Life.

In line with the above, Waluyo explained that the e-voting can be applied effectively and produce the results of the counting of votes that can be recognized by the entire layer of society, in addition to the principles of Luber and Jurdil in the electoral system Now, the application of e-voting must be based on the following principles [18]:

- Eligibility and authentication, the only authorized selector should be able to choose;

- Uniqueness (uniqueness), selector can only choose one

- Accuracy, the electoral system should record the sound correctly;

- Integrity, the person should not be altered, forged, or removed without detection;

- Reliability, electoral system must work firmly, without losing any person, even in the face of various failures, including the failure of voting engines and total loss of Internet communication;

The principles and aspects above must be fulfilled before the e-voting is applied in Indonesia. The Constitutional Court of INDONESIA has also given a prerequisite to this, although it has not been detailed in the principles and aspects above. Evidenced by the impossibility of the test of Law No. 32 in 2004 about the regional government that does not allow the evoting for elections because the article 88 only allows to test. The COURT granted the e-voting with a record, which is fulfilled by the cumulative requirement by not violating the five principle elections: Luber and Jurdil. In addition, the implementing areas must be prepared from the technology side, financing, human resources, software, as well as the community is ready [16].

Next, to find out the effectiveness of electronic voting implementation in the implementation of elections, researchers use the measurement indicators effectiveness according to Richard Steers to make it easier to understand the various Problems that occur at the research site. Steers ' effectiveness measurement indicators are efficiency, satisfaction, and adaptation [19].

\section{CONCLUSION}

Legal studies regarding the implementation of the elections using electronic voting are:

- Article 1 Figure 6 of law No. 19 of 2016 on electronic information and transactions mentioning electronic system implementation is the utilization of electronic systems by the organizers of the state, people, business entities, and/or society. So KPU as state institutions become one of the organizers of electronic systems, it is also in accordance with article 1 Number 4 government 
regulation No. 82 year 2012 on the implementation of electronic systems and transactions.

- The verdict of the Constitutional Court No. 147/PUUVII/2009 which in the its verdict of the court declares article 88 of the Law Number 32 year 2004 concerning the local government is a conditional constitutional to article 28C paragraph (1) and paragraph (2) of the law National policy of the Republic of Indonesia year 1945 so said, in Article 88 Act number 32 year 2004 about local government is also interpreted using the E-voting method with cumulative requirements.

People in Indonesia are ready to welcome electronic voting with keyword socialization. The implementation of the elections using electronic voting in the perspective of openness is the establishment that requires mature preparation of the human resources, data on the management of the selection, procedures and the e-voting device itself, and requires the configuration of the list of voters and candidates before voting, the implementation of voting and voting in the TPS, and the delivery and recapitulation of the Voice acquisition thoroughly. Further, it is necessary to socialize with voters and candidates, the provision of e-voting devices, electronic voting simulations and sound calculations, and device certifications to ensure a direct, public, free and confidential and honest election principle and Fair can be fulfilled. The use of e-voting in elections will not work well if the process or the stages are not working properly. The socialization that is the basis of the socio legal implications regarding the use of new ways in this election is not to be fulfilled.

\section{REFERENCES}

[1] M. Lubis and A.R. Lubis, "Dealing with Voters' Privacy Preferences and Readiness in Electronic Voting," Indonesian Journal of Electrical Engineering and Computer Science, vol. 11, no. 3, pp. 994-1003, 2018.

[2] M. Lubis, M. Kartiwi, and S. Zulhuda, "Decision to casting a vote: An ordinal regression statistical analysis," In The 5th International Conference on Information and Communication Technology for The Muslim World (ICT4M), pp. 1-6), 2014

[3] S. Risnanto, "Aplikasi Pemungutan Suara Elektronik/E-Voting Menggunakan Teknologi Short Message Service dan At Command," Jurnal Teknik Informatika, vol. 10, no. 1, 2017.

[4] W. Budiharto and M. Meiliana, "Prediction and analysis of Indonesia Presidential election from Twitter using sentiment analysis," Journal of Big data, vol. 5, no. 1, pp. 51, 2018.
[5] A. Hartami and P.W. Handayani, "The critical success factors of evoting implementation in indonesian local elections: The case of jembrana regency election," In ECEG2012-Proceedings of the 12th European Conference on e-Government: ECEG, p. 336, 2012.

[6] B.A. Olken, "Direct democracy and local public goods: Evidence from a field experiment in Indonesia," American political science review, vol. 104, no. 2, pp. 243-267, 2010.

[7] M. Lubis and M. Kartiwi, "Privacy concern and perceived benefits towards privacy and election in Indonesia," In The 5th International Conference on Information and Communication Technology for The Muslim World (ICT4M), pp. 1-6, 2014.

[8] I.K. Nasution, "Ethnicity, Democracy and Decentralization: Explaining the Ethnic Political Participation of Direct Election in Medan 2010," Procedia Environmental Science, vol. 20, pp. 496-505, 2014.

[9] T. Kohno, A. Stubblefield, A.D. Rubin, and D.S. Wallach, "Analysis of an electronic voting system. In IEEE Symposium on Security and Privacy," Proceedings IEEE, pp. 27-40, 2004.

[10] R.W. Liddle and S. Mujani, "Leadership, party, and religion: Explaining voting behavior in Indonesia," Comparative Political Studies, vol. 40, no. 7, pp. 832-857, 2007.

[11] T. Haryadi, E. Praptono, and E.A. Pratama, "Implikasi Hukum Terhadap Pembatasan Peran Serta Aparatur Sipil Negara dalam Proses Politik di Indonesia," DIKTUM UPS TEGAL, vol. 7, no. 1, pp. 43-67, 2019.

[12] I.M. Rodiana, B. Rahardjo, and W.A. Ida, "Design of a Public Key Infrastructure-based Single Ballot E-Voting System," In 2018 International Conference on Information Technology Systems and Innovation (ICITSI), pp. 6-9, 2018.

[13] A. Prosser, R. Kofler, and R. Krimmer, "Deploying electronic democracy for public corporations," In International Conference on Electronic Government, pp. 234-239, 2003.

[14] B.A. King and N.E. Youngblood, "E-government in Alabama: An analysis of county voting and election website content, usability, accessibility, and mobile readiness," Government Information Quarterly, vol. 33, no. 4, pp. 715-726, 2016.

[15] M. Hapsara, "E-voting Indonesia: framing the research," In 2014 9th Iberian Conference on Information Systems and Technologies (CISTI), pp. 1-6, 2014

[16] B.C. Burden, D.T. Canon, K.R. Mayer, and D.P. Moynihan, "Election laws, mobilization, and turnout: The unanticipated consequences of election reform," American Journal of Political Science, vol. 58, no. 1, pp. 95-109, 2014

[17] E.A. Pratama, Optimalisasi pengelolaan zakat sebagai sarana mencapa kesejahteraan sosial (Sebuah studi di badan amil zakat kota Semarang). Doctoral dissertation, Univarsitas Negeri Semarang, 2013.

[18] M. Lubis, M. Kartiwi, and Y. Durachman, "Assessing privacy and readiness of electronic voting system in Indonesia," In 2017 5th International Conference on Cyber and IT Service Management (CITSM), pp. 1-7, 2017

[19] J. Jillbert, "Feasibility Study of Electronic Voting in Developing Countries: A Indonesia Context," Journal of Systems Integration, vol. 9 , no. 3, pp. 26-33, 2018. 